\title{
Labyrinth Seal of Aircraft Turbine Engine Air Flow Calculation at High Viscosity
}

\author{
Michal Čižek ${ }^{1, *}$, Tomáš Vampola ${ }^{1}$ \\ Center of Aviation and Space Research, Faculty of Mechanical Engineering, Czech Technical University in Prague, Jugoslávských partyzánů 1580/3; \\ 16000 , Prague 6; Czech Republic
}

\begin{abstract}
This paper describes a CFD calculation of aircraft turbine engine labyrinth seal. The geometry of labyrinth seal shows that the air flow is very viscous. Based on the CFD calculation it was prepared some analysis of Reynolds numbers, Mach numbers and total temperature with different rotational speeds. Based on this analysis it is possible to improve the standard design steps of labyrinth seals of aircraft turbine engines. It should be helpful for thermodynamic and aircraft engineers.
\end{abstract}

Keywords: Labyrinth Seal, Turbine Engine, CFD, Total Temperature, Radial Clearance.

\section{Introduction}

The labyrinth seal is important part of the aircraft turbine engine. Design of the labyrinth seal is easy and old, because initial researches of design were started parallel with steam turbines design [1]. Reason why was labyrinth seal design in steam turbines was eliminated the secondary air flow and increase the efficiency of the turbine. The steam turbine does have labyrinth seal primary in top of the blades to reduce the flow in cavity between rotor blades and stator part. In aircraft turbines is different situation. The secondary air flow is flow what is used for hot parts cooling. For large engines is used the similar logic reduce the secondary air flow in top of the blades, because large engines do have high diameter. In smaller engines is not possible, because there is not area for used. Other reason for using the labyrinth seal is eliminate the air flow in cavities between rotating shaft and stator parts.

Aim of these article is detail analyze and describe the air flow there in different option in aircraft turbine engine. Generally, can be said, that the labyrinth seal is noncontact seal. It is logic, because in high rotationally speed and in high temperature is not possible use the contact sealing (e.g. piston rings).

The labyrinth seal in aircraft turbine engine is describe from rotational teeth (rotor) and straight wall like (stator) [2], [3] and [4] or Figure 1 - flow is coming from left to right site. Between these two elements is located the air flow cavity where is the air flow of the gas. As apparent from the picture the important parts are profile of the teeth, rotational speed and radial clearance between the rotating and non-rotating parts [5]. With precision settings of the radial clearances and geometry of the flow cavity it should be possible to improve the performance parameters of the engine. Thermodynamically it is an expansion to the ambient conditions in all teeth. The kinetic energy from the rotating shaft moved to the heat the seal flow in sealing cavity between rotor and stator [2]. Based on CFD tools it is possible to detail describe the seal flow and evaluate calculated data [6]. The previous research focused only on the elimination of the air flow [7] and total temperature increase through the teeth [8]. The 
last parameter is important for acceptable design the seal in real machine. Based on the information of total temperature increase, the design engineer can better select the material of the sealing. If the material is abrasive, the total temperature parameter is even important [9]. In this article will show the influence of the rotational speed on the Reynolds number, Mach number and total temperature parameters.

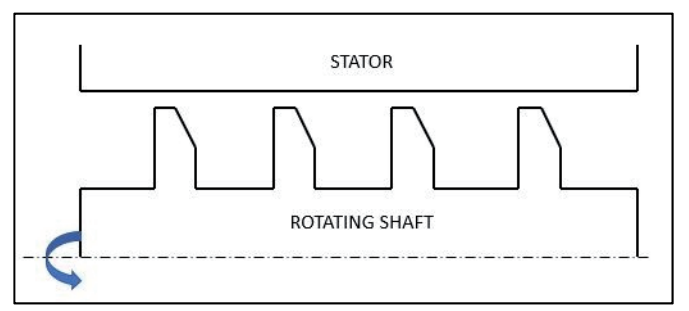

Figure 1: Labyrinth seal scheme.

\section{CFD Calculation}

\subsection{Geometry description}

The 3D CFD calculation geometry consist of three $5 \mathrm{deg}$ annular volumes. $1^{\text {st }}$ volume is "Inlet control volume" - Figure 2, $2^{\text {nd }}$ volume is "Labyrinth seal volume" where the teeth are in rotor like in Figure 1 and Figure 3 - and the last volume is "Exit control volume" - Figure 2 [8]. This configuration was chosen because the inlet control volume guarantees good inlet total pressure distribution. Labyrinth seal volume guarantees good description of the sealing and exit control volume guarantees good air flow to the ambient conditions.

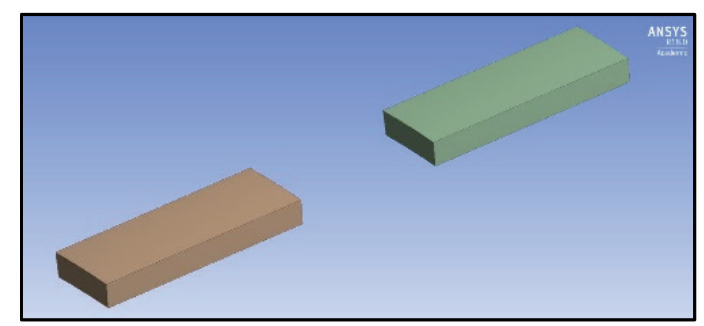

Figure 2: Inlet (left) and exit (right) control volume.

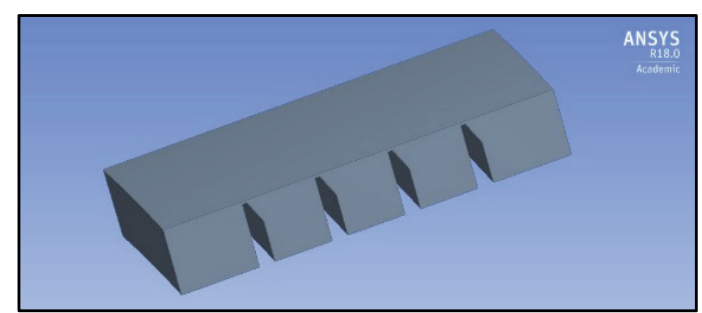

Figure 3: Labyrinth seal volume.

\subsection{Calculation mesh}

The calculation mesh was prepared in ANSYS Meshing v.18 software. Based on the geometry analysis was decided that the important area is radial clearance between stator wall and rotating teeth - Figure 4.

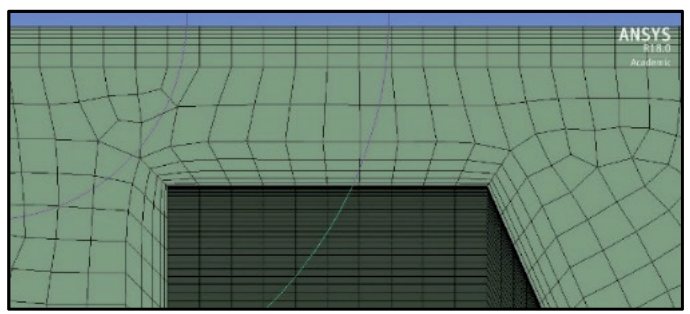

Figure 4: Calculating mesh in radial clearance.

The mesh was created like a mapped mesh with using Sweep method. The mesh of labyrinth seal volume does have $2.09 \mathrm{M}$ of hexahedral elements Figure 5.

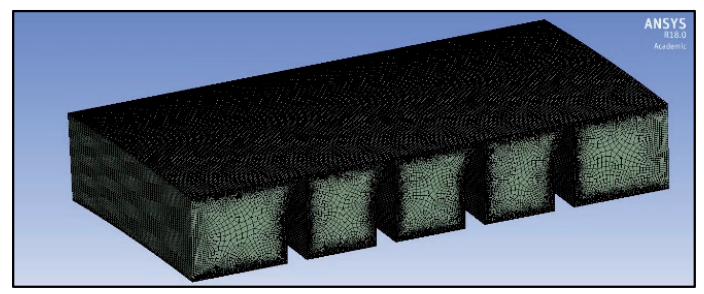

Figure 5: Labyrinth volume mesh.

In labyrinth volume mesh is important to define well the walls influence. In radial clearance area was defined 14 rows of elements. It is appropriate for good description of the air flow. In inlet and exit control volumes was used similar strategy - Sweep method. Both volumes have $2.6 \mathrm{M}$ of hexahedral elements - Figure 6.

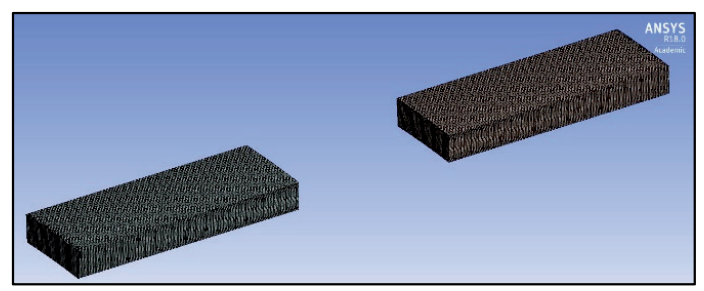

Figure 6: Inlet and exit control volumes mesh.

\subsection{Boundary conditions}

Boundary conditions are important thing for all calculations. Boundary conditions was defined in 
ANSYS CFX-Pre v. 18 software. Basic setting is that the labyrinth seal volume is rotating volume. Volume is rotating at constant rotationally speed. In stator wall was defined "Counter rotating wall" condition (i.e. that the wall is rotating at reverse speed with the same value - [10]). In inlet control volumes was defined the total pressure ant total temperature inlet. In exit control volume was defined static pressure outlet. Between volumes was defined interface with Frozen rotor mixing plane model. Due to this, it is possible to connect volumes with different rotational speed - [10] and [8]. In borders of all volumes were defined periodic conditions Figure 7. Values of boundary conditions was defined for standard operational conditions of aircraft turbine engine. Air ideal gas was set like a main flow medium. Based on [11] and [12] was used the k- $\varepsilon$ turbulent model. Calculations were converged $1 \mathrm{e}-04$ in 1000 iterations.

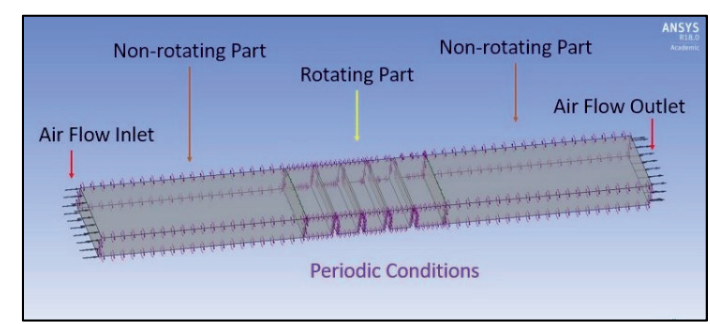

Figure 7: Boundary conditions.

\section{$2.41^{\text {st }}$ Calculation and mesh evaluation}

In $1^{\text {st }}$ research was calculated total temperature, Mach Number and Reynolds number in constant rotating speed but with different radial clearance. Corrected radial clearance [-] was defined by formula (1), where $R C$ is real radial clearance $[\mathrm{mm}]$ and $R C_{C H}$ is radial clearance in seal without teeth $[\mathrm{mm}]$.

$$
R C_{\text {CORR }}=\frac{R C}{R C_{C H}}
$$

Reynold number [-] was calculated based on formula (2):

$$
R_{e}=\frac{w_{s} \cdot d}{\mu}
$$

where $w_{s}$ is velocity $\left[\mathrm{m} \cdot \mathrm{s}^{-1}\right], d$ is reference diameter (i.e. middle diameter of seal) [m] and $\mu$ kinematic viscosity $\left[\mathrm{m}^{2} \cdot \mathrm{s}^{-1}\right]$ - which is defined by (3):

$$
\mu=\frac{\eta}{\rho}
$$

where $\eta$ dynamic viscosity [Pa.s] and $\rho$ is density $\left[\mathrm{kg} \cdot \mathrm{m}^{-3}\right.$.

Corrected total temperature [-] is defined by formula (4):

$T_{\text {CCORR }}=\frac{T_{C}}{T_{\text {CREF }}}$

where $T_{C}$ is total temperature $[\mathrm{K}]$ and $T_{C R E F}$ is reference total temperature $[\mathrm{K}]$.

Before results was analyzed the quality of calculated mesh. Coarse mesh was defined by $0.5 \mathrm{M}$ of hexahedral elements of labyrinth seal volume. Fine mesh was defined by $5 \mathrm{M}$ of hexahedral elements of labyrinth seal volume. Inlet and exit control volumes are the same as in mesh in chapt. 2.2. Parameters difference between value on $1^{\text {st }}$ and on the last teeth were analyzed in following charts (Figure 8 and Figure 9) - reference mesh is mesh from chapt. 2.2.

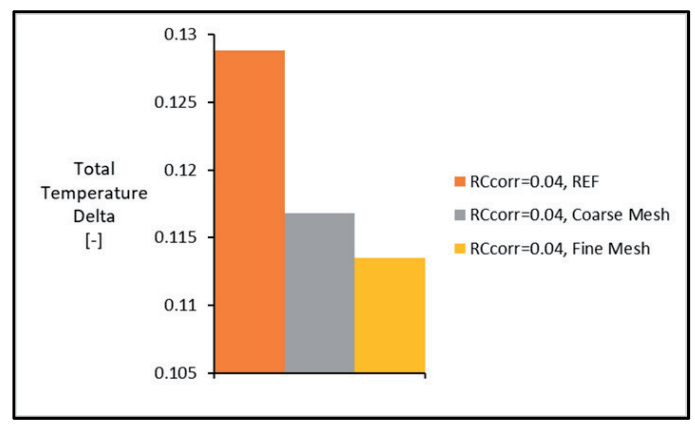

Figure 8: Mesh comparison.

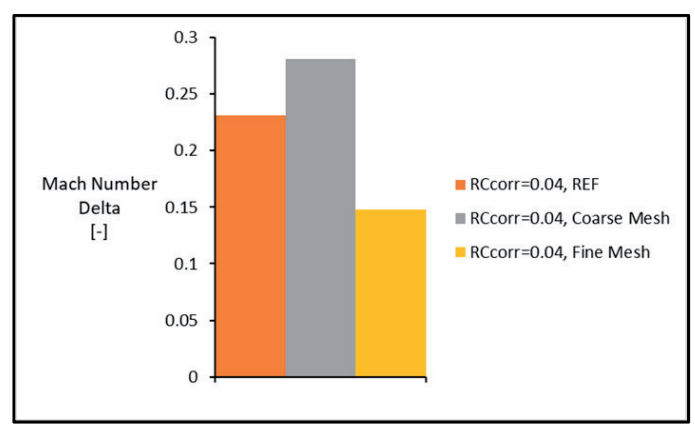

Figure 9: Mesh comparison.

Results from mesh comparison is that the calculating mesh (presented in 2.2) is usable for next analysis.

For the $1^{\text {st }}$ time were analyzed the velocity vectors in different radial clearance: 


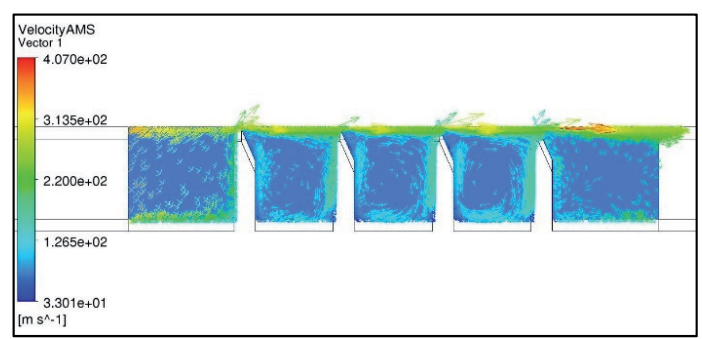

Figure 10: Velocity vectors with $\mathrm{RC}_{\text {CORR }}=0.02$.

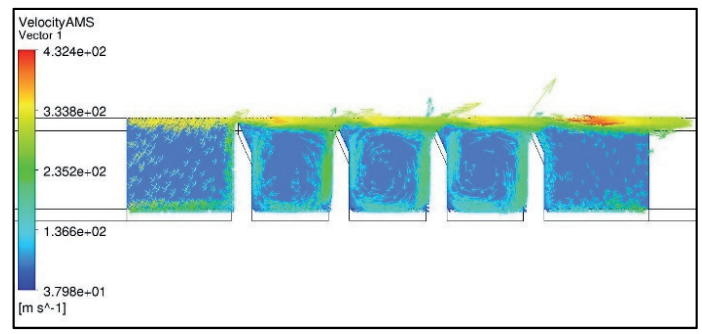

Figure 11: Velocity vectors with $\mathrm{RC}_{\text {CORR }}=0.04$

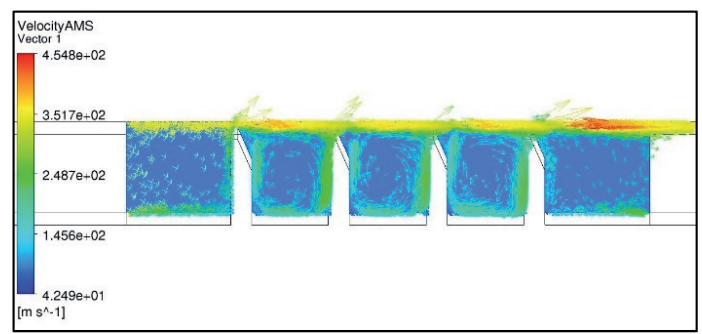

Figure 12: Velocity vectors with $\mathrm{RC}_{\mathrm{CORR}}=0.06$.

The velocity vectors in previously (Figure 10, Figure 11 and Figure 12) pictures are important do check the swirl between the teeth. It is dominant factor for good sealing. The pictures show that the swirl is fully developed. It is good point for next analysis.

The Mach number field shows us that the maximum value is in the last teeth, where is expansion to the ambient conditions. Followed by the plots of trendlines of total temperature (Figure

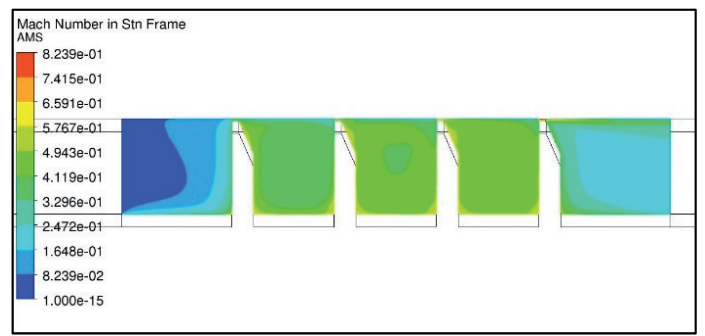

Figure 13: Mach number field with $\mathrm{RC}_{\mathrm{CORR}}=0.02$.

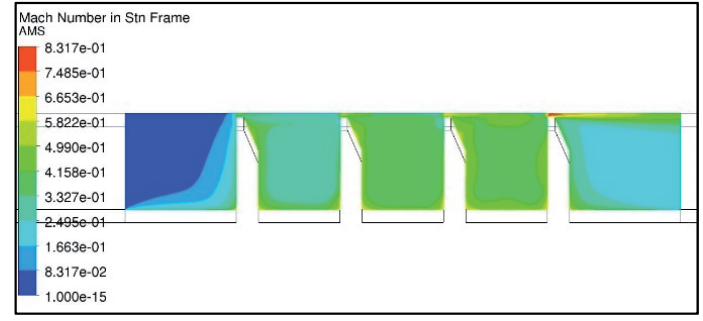

Figure 14: Mach number field with $\mathrm{RC}_{\text {CORR }}=0.04$.

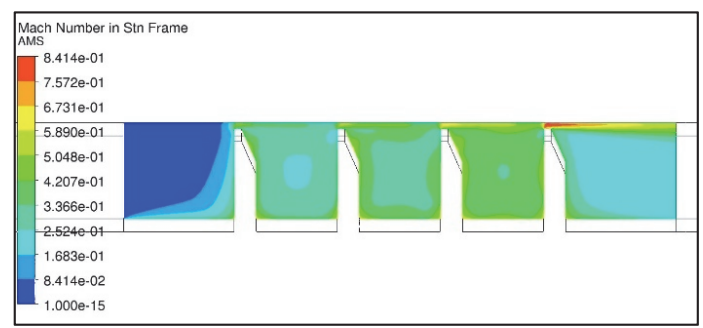

Figure 15: Mach number field with $\mathrm{RC}_{\text {CORR }}=0.06$.

16), Mach number (Figure 17) and Reynolds number (Figure 18) through the teeth with different radial clearance but in constant rotational speed.

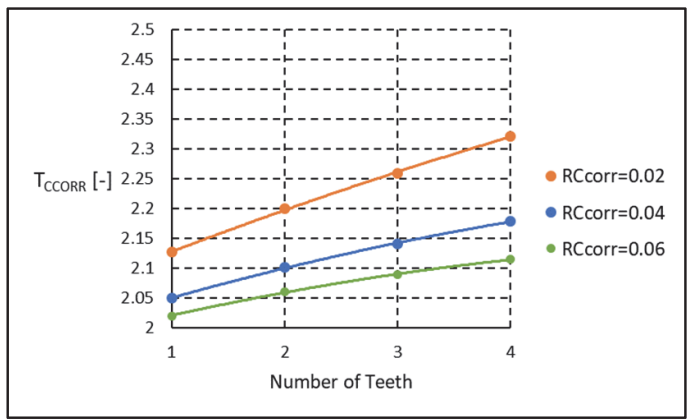

Figure 16: Total temperature.

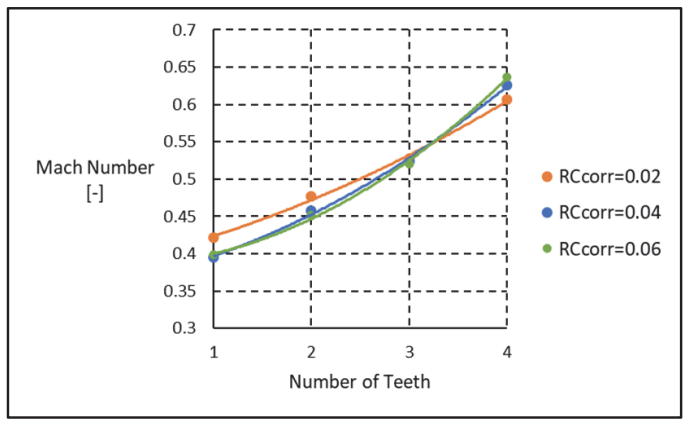

Figure 17: Mach number. 


\subsection{Different speed}

Based on previously calculation was decided to continue the calculation with different rotational speed. Reference rotational speed is rotational speed, which was use in chapt. 2.4. So, corrected rotational speed [-] was defined by formula (5):

$n_{\text {CORR }}=\frac{n}{n_{R E F}}$

where $n$ is rotational speed $\left[\mathrm{min}^{-1}\right]$ and $n_{R E F}$ is reference rotational speed $\left[\mathrm{min}^{-1}\right]$.

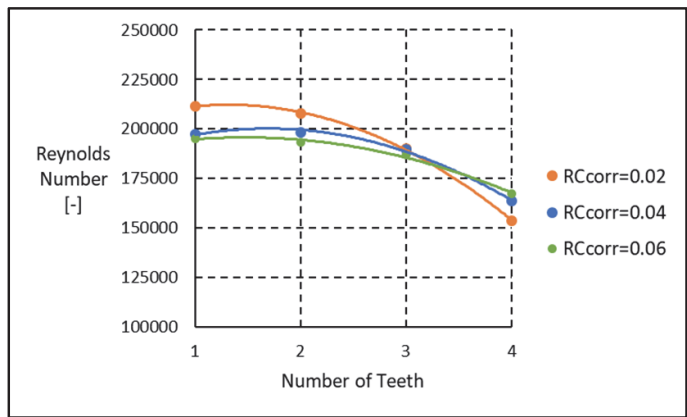

Figure 18: Reynolds number.

Primary calculations were focused to analyze total temperature increase in different speeds. Totally were calculated 7 points of constant speeds. In next charts are present the same thermodynamic parameters like in 2.4 but with different speeds:

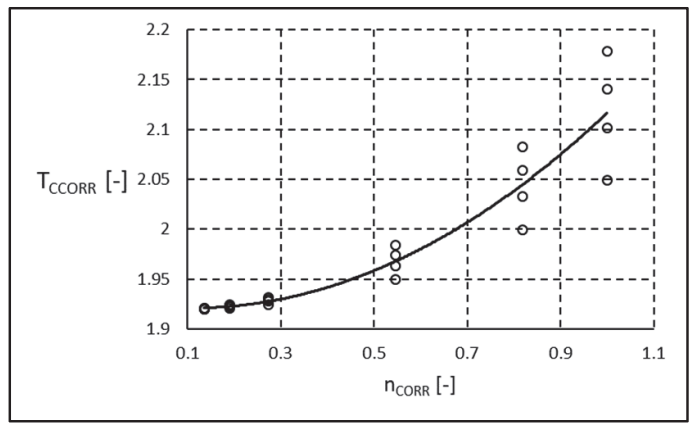

Figure 19: Total temperature with different speeds.

As we can see from Figure 19, the corrected total temperature increase is primary in higher rotational speed - in maximal speed is $\sim 2.12$. It is not so small. From Figure 20 we can see that the Mach number increase is in higher rotational speed too. It is logic, because in higher speed the velocity in last teeth is maximal (similar result is in Figure 15). There is a maximal expansion to the ambient. In the Figure
21 we can see that the maximal value of Reynolds number is $\sim 180 \mathrm{k}$. It means that the flow in labyrinth seal is very turbulent (similar results is seen from velocity vectors Figure 10).

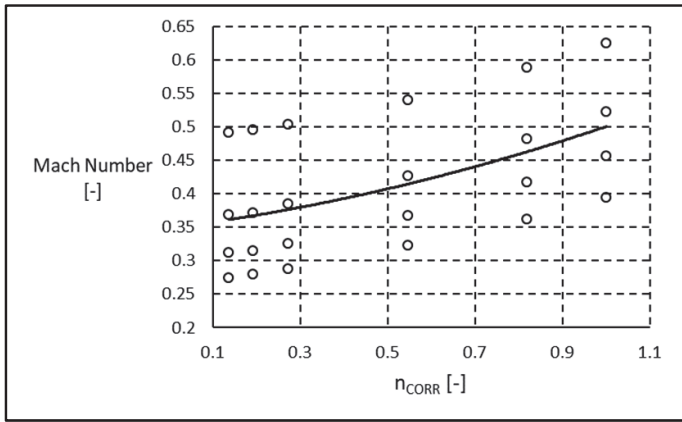

Figure 20: Mach number with different speeds.

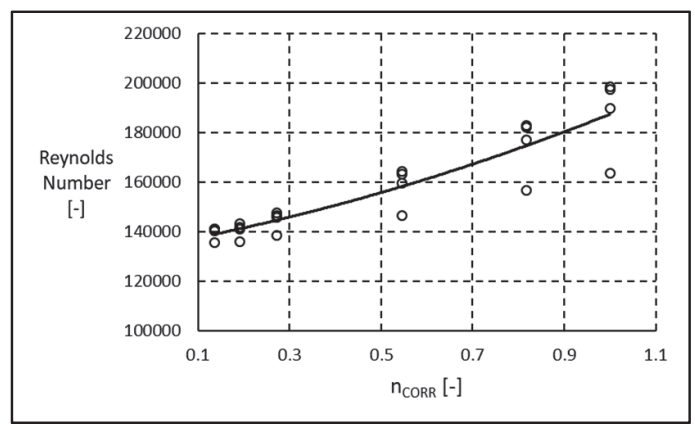

Figure 21: Reynolds number with different speeds.

\subsection{Different speeds and different radial clearance}

Based on the result from chapt. 2.5 was focused analyze more points corrected total temperature increase than it is chapt. 2.5. but in different corrected radial clearance. It was analyzed only corrected total temperature [-] difference was calculated based on formula (6):

$\Delta T_{\text {CCORR }}=T_{\text {CCORRL }}-T_{\text {CCORRF }}$

where $T_{\text {CCORRL }}$ is corrected total temperature in last teeth [-] and $T_{\text {CCORRF }}$ is corrected total temperature in first teeth [-]. Totally were calculated 14 speeds with 2 corrected radial clearances -0.04 and 0.15 . As we can see from Figure 22 the total temperature increase is higher $(\sim 0.16)$ with using small radial clearance and with higher radial clearance it is smaller ( 0.04). It sounds logic, because width small radial clearance is there higher Mach number (Figure 13 and Figure 17) and the cavity is heating up. 


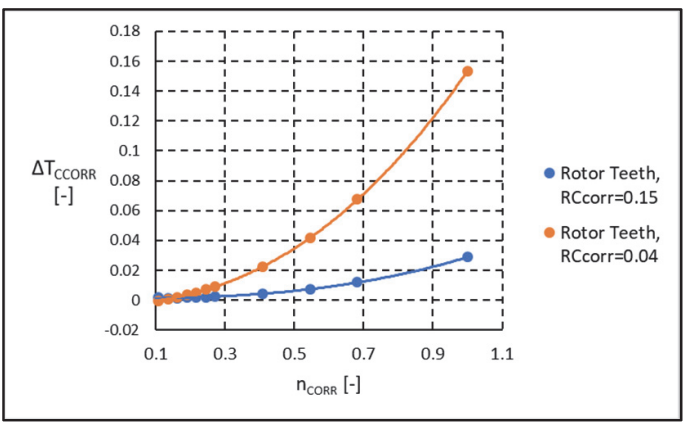

Figure 22: Corrected total temperature increase with different radial clearance.

\section{Evaluation test}

The total temperature increase was evaluated in real turboprop engine. Center of Aviation and Space Research (CASR) is partnering with GE Aviation. GE Aviation is currently developing new turboprop engine called Catalyst. CASR tested the Catalyst engine and during the test were tested labyrinth seals too.

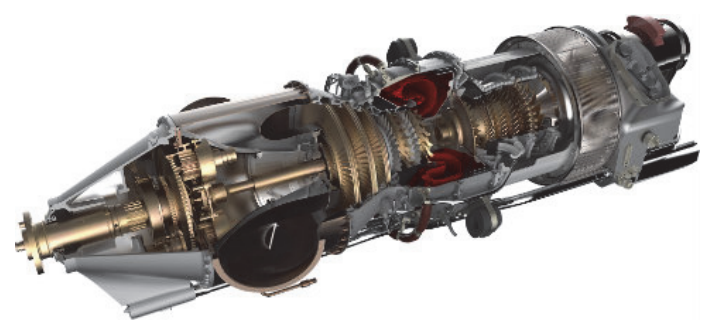

Figure 23: GE Catalyst Engine [13].

The test was focuses to the total temperature increase. In typical labyrinth seal were installed thermocouples in air flow inlet and air flow outlet. Scheme of positions of thermocouples is in Figure 24.

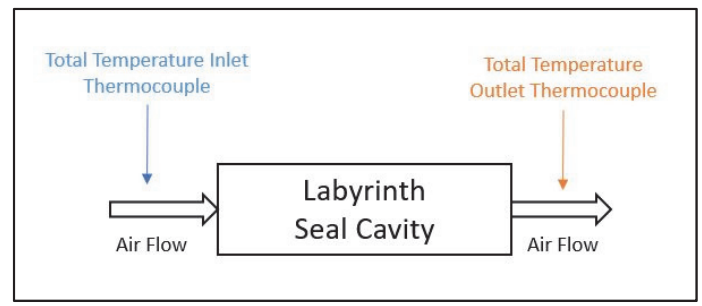

Figure 24: Measurement scheme.

The test was scheduled like measurement of total temperature inlet and total temperature outlet with different speeds. Geometry of Labyrinth Seal Cavity was designed like a 4 rotating teeth with constant corrected radial clearance 0.04. It was measured 11 steady state points. Both thermocouples had $\pm 4 \mathrm{~K}$ accuracy.

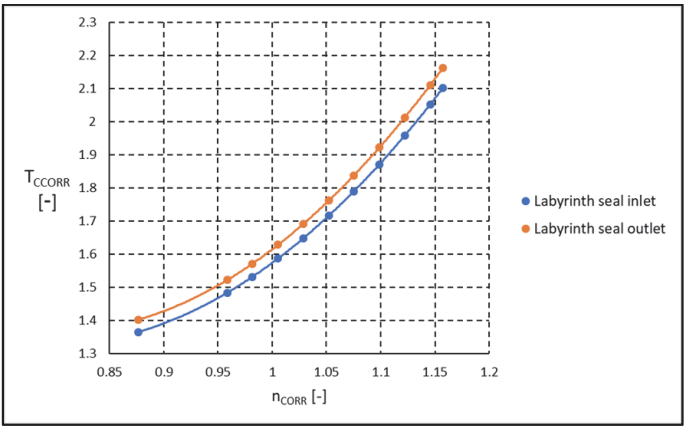

Figure 25: Total temperature measurement.

It is obvious from the measurement, that the corrected total temperature delta is $-\sim 0.08$.

\section{Results and Discussion}

The main aim of this article is more describe and analyzed the air flow during the labyrinth seal of turbine engines more than in previously work. CFD method was chosen for analysis of labyrinth seal. Based on ANSYS Workbench tools were modeled typical labyrinth seal what was presented in chapt. 2.1. Analysis of calculating mesh was described in 2.2. Boundary conditions of the calculation were presented in chapt. 2.3. For $1^{\text {st }}$ calculation was analyzed the mesh of their quality - chapt. 2.4 - and it was calculated 3 variants of radial clearance. After calculation it was found, that the total temperature was increased which is contrary with [1] - similar results was presented in [8]. But the previously literature ([5] and [7]) was analyzed steam turbines labyrinth seal application. In aircraft turbine engine are different conditions. The workpoint of steam turbines is in constant rotational speed approx. $2500\left[\mathrm{~min}^{-1}\right]$ [1]. In this article different rotational speed. As can be seen from the trendlines - Figure 16- the total temperature is not a constant value. With lesser radial clearance the total temperature increases more. Total temperature with different speed - Figure 19 - increase. Mach number trendlines through the seal- Figure 14 and Figure 17- shows, that maximal value is in the last teeth expansion to the ambient conditions. Mach number with different speed increases - Figure 20. Reynolds number trendlines through the seal - Figure 18 - 
is approx. similar in $1^{\text {st }}$ and in the last teeth. But it shows, that the air flow is so turbulent. Reynolds number with different speeds - Figure 21 - increase. It is, because with higher rotationally speed the circumferential swirl is more developed. Based on preliminary results was decided to evaluate the calculation in test facility - chapt. 3. It was measured the inlet total temperature and in outlet of the labyrinth seal - Figure 24 - with different speed. Measurement results is that the total temperature increase with different speed - Figure 25. It is thanks to more developed circumferential swirl between the teeth (e.g. see velocity vectors in Figure 11). This information is important to the labyrinth seal engineers, who can better design material and manufacturing technology. For the future work should be interesting evaluate this result in laboratory measurement. In CASR should be prepare test rig for better measurement of labyrinth seal in the future.

\section{Acknowledgments}

Authors acknowledge support from the ESIF, EU Operational Programme Research, Development and Education, and from the Center of Advanced Aerospace Technology (CZ.02.1.01/0.0/0 .0/16_019/0000826), Faculty of Mechanical Engineering, (zech Technical University in Prague.

\section{References and Notes}

[1] Ščeglajev Av. V., 1983, Parní turbíny, Státní nakladatelství technické literatury

[2] Jerie J., 1981, Teorie motorů, Ediční středisko ČVUT Praha 1

[3] Zimmermann H.,Wolff K. H., 1998, Air System Correlations: Part 1 - Labyrinth Seals, ASME 1998 International Gas Turbine and Aeroengine Congress and Exhibition

[4] Bondarenko G.A., Baga V.N., Bashlak I.A,.2014, Flow Simulation a labyrinth seal, Applied Mechanics and Materials

[5] Ilieva G., Pirovsky C., 2019, Labyrinth seals with application to turbomachinery, Materials Science \& Engineering Technology

[6] Allcock D., Ivey P., Turner J., 2012, Abradable Stator Gas Turbine Labyrinth Seals: Part 1 Experimental Determination and CFD Modeling of Effective Friction Factors for Honeycomb Materials, ASME 2012

[7] Furst J., 2015, Numerical simulation of flows through Labyrinth seals, Applied Mechanics and Materials

[8] Čižek M., 2019, 3D CFD Research of Labyrinth Seal Cavities of Aircraft Turbine Engine, New Trends in Aviation Development 2019
[9] Hawkins L., Childs D., Hale K., 1989, Experimental Results for Labyrinth Gas Seals With Honeycomb Stators: Comparisons to Smooth-Stator Seals and Theoretical Predictions, Journal of Tribology

[10] ANSYS Help Viewer 18.0, 2016

[11] Tong S. K., Kyu S. Ch., 2009, Comparative analysis of the influence of labyrinth seal configuration on leakage behavior, Journal of Mechanical Science and Technology

[12] Č́žek M., Pátek Z., 2020, On CFD Investigation of Radial Clearance of Labyrinth Seals of a Turbine Engine, Acta Polytechnica

[13] General Electric Catalyst, https://en.wikipedia.org/wiki/ General_Electric_Catalyst 